Plant Tissue Cult. \& Biotech. 20(1): 13-20, 2010 (June)

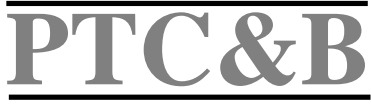

\title{
Micropropagation of Ophiorrhiza eriantha Wight. through Leaf Explant Cultures
}

\author{
V. K. Jaimsha Rani, P. V. Fijesh and Jose Padikkala* \\ Amala Cancer Research Centre, Amala Nagar, Thrissur, Kerala-680 555, India \\ Key words: Camptothecin, Leaf explants, Ophiorrhiza eriantha, Micropropagation
}

\begin{abstract}
Leaf explants of Ophiorrhiza eriantha cultured in MS supplemented with the combination of NAA $4 \mathrm{mg} / \mathrm{l}$ and BA $0.5 \mathrm{mg} / \mathrm{l}$ induced higher callus growth. The maximum number of shoots were produced from callus on the MS supplemented with BA $5 \mathrm{mg} / \mathrm{l}$. The regenerated shoots were transferred into the auxin containing medium for rooting and IBA $3 \mathrm{mg} / \mathrm{l}$ supplemented medium produced maximum number of roots per shoot. Camptothecin (anticancer drug) was isolated from $O$. eriantha wild grown plant and in vitro regenerated plants, and was confirmed by LC-MS-MS. The camptothecin content in wild grown plant, callus and regenerated plants were quantified by HPLC system.
\end{abstract}

\section{Introduction}

Camptothecin (CPT), a plant originated alkaloid, is well-known for its potential anticancer activity due to its ability to inhibit DNA topoisomerase I (Kjeldsen et al. 1992) an enzyme involved in relaxing super coiled DNA. Over a dozen of new CPT derivatives are currently in various stages of preclinical and clinical development (Zunino and Pratesi 2004). Among them two derivatives, topotecan and irinotecan have been widely used for the treatment of cancer over the world (Lorence et al. 2004).

CPT was first identified in Camptotheca acuminate (Wall et al. 1966) and to date several CPT producing plants have been identified. Among them the genus Ophiorrhiza has got great importance after the isolation of CPT from O. mungos by Tafur et al. 1976. Various other Ophiorrhiza species such as O. pumila, O. filistipula (Saito et al. 2001) and O.rugosa (Vineesh et al. 2007) have also been reported for the presence of camptothecin. Considering the clinical importance of CPT and its derivatives it is important to discover new sources and to develop a sustainable alternative production method for this valuable drug. Plant tissue culture have been used as one of the method of producing these high cost compound.

*Author for correspondence. <jpadikkala@rediffmail.com>. 
The objective of the present study was to develop an efficient plant regeneration protocol for O. eriantha and to detect CPT in wild grown plant, callus and in vitro regenerated plantlets.

\section{Materials and Methods}

Plant samples were collected from the forests of Mannavan chola, Idukki, Kerala, India. Tender leaves were taken as explants and were cleaned thoroughly under running tap water. Then washed with an aqueous solution of $0.1 \%$ of Tween 20 and again washed with distilled water for five - six times. The explants were then surface-sterilized with an aqueous solution of $0.1 \% \mathrm{HgCl}_{2}$ for $3 \mathrm{~min}$ and followed by repeated washing with sterile distilled water under sterilized laminar flow hood. The leaf margins were removed along with the tip and basal portions. The leaf sections were aseptically inoculated into the MS. The $\mathrm{pH}$ of the medium was adjusted to 5.7 using $0.1 \mathrm{~N} \mathrm{NaOH}$ or $0.1 \mathrm{~N} \mathrm{HCl}$ prior to adding $0.75 \%$ agar (Himedia, Mumbai). The media were steam sterilized at $121^{\circ} \mathrm{C}$ for $20 \mathrm{~min}$ and allowed to cool at room temperature. The cultures were incubated under a $16 \mathrm{hrs}$ photoperiod in cool white florescent light $25 \mu \mathrm{mol} \mathrm{m} \mathrm{m}^{-2} \mathrm{~s}^{-1}$ and maintained at a constant temperature of $25 \pm 2^{\circ} \mathrm{C}$. The cultures were maintained by subculturing at four weeks intervals to fresh medium with the same composition. Different concentrations of NAA either individually $(0.5-5 \mathrm{mg} / \mathrm{l})$ or in combination of BA $(0.5-5 \mathrm{mg} / \mathrm{l})$ tested for their effect on callus formation from leaf explants.

To induce shoot regeneration, well-established compact calluses ( $\sim 500 \mathrm{~g}$ fresh weight) were transferred to MS supplemented with different combinations of BA (1 - $5 \mathrm{mg} / \mathrm{l})$ alone or in combination with NAA (3 - $4 \mathrm{mg} / \mathrm{l})$. The number of shootbuds induced on $500 \mathrm{mg}$ of calluses was counted after eight weeks. Some of the 1 - 2 week-old shoot buds were harvested for CPT analysis.

Half strength of MS supplemented with $3 \%(\mathrm{w} / \mathrm{v})$ sucrose was used for rooting experiments. For root differentiation in vitro differentiated elongated shoots were excised from culture grown on MS supplemented with BA $5 \mathrm{mg} / \mathrm{l}$. The excised shoots were cultured on four concentrations of NAA (1 - $4 \mathrm{mg} / \mathrm{l})$, IBA (1 - $4 \mathrm{mg} / \mathrm{l})$ and IAA (1 - $4 \mathrm{mg} / \mathrm{l})$. Twelve shoots were used per treatment with

three replications. Data were recorded on percentage of rooting and root number after four weeks on rooting media.

Well rooted healthy plantlets were removed from the culture medium, the roots were washed gently with tap water to remove medium and then transferred to earthen pots with sand and soil $(1: 1)$. After transplantation the plantlets were watered and covered with polyethylene bags to maintain humidity. Afterwards, the hardened plants were gradually transferred to the field. 
For the isolation of CPT the air dried O. eriantha plants were ground to fine powder (100 g) and extracted with methanol using Soxhlet apparatus (Rotek, India. PVT Ltd.). The methanol extract was evaporated to dryness under vaccum. The dried extract was dissolved in $3 \% \mathrm{HCl}$ and extracted with chloroform. After extraction the $\mathrm{pH}$ of the $\mathrm{HCl}$ portion was increased to $\mathrm{pH} 10$ by adding $\mathrm{NH}_{3} \mathrm{OH}$ and extracted again with chloroform. The chloroform extract was evaporated under vacuum and subjected to preparative TLC using solvent system, chloroform and methanol (24:1). The TLC plates were visualized under UV (250 $\mathrm{nm}$ ) and the blue fluorescent band containing CPT was scraped out and eluted with methanol. The isolated CPT and standard CPT were dissolved in acetonitrile and analysed using LC-MS-MS system.

For the quantification of CPT in O. eriantha, the air dried wild plants, and lyophilized in vitro cultured plantlets and calluses were powdered and were subjected to extraction with methanol. The filtrate was concentrated to dryness in a rotary vacuum evaporator at $37^{\circ} \mathrm{C}$. The concentrate was dissolved with acetonitrile : water $(24: 1)$ and centrifuged for $5 \mathrm{~min}$ at $2000 \mathrm{rpm}$. The supernatant was collected and was filtered with $0.45 \mu \mathrm{m}$ nylon syringe filter before HPLC analysis. The HPLC system is a Shimadzu SPD-10AVP HPLC system equipped with a multi solvent delivery system and an UV-VIS detector. The column was a Purospher star column rp-18, end capped, $5 \mu \mathrm{m}, 250 \times 4.60$ mm (Merck, Germany). The mobile phase was composed of acetonitrile and water $(60: 40)$ with isocratic elution. The flow rate was $1 \mathrm{ml} /$ minute, with UV absorbance detection at $256 \mathrm{~nm}$ and sample injection volume was $20 \mu$. The column temperature was kept at $25^{\circ} \mathrm{C}$. The CPT in samples were quantitatively identified by comparing the retention time and quantified by integrating peak areas with standard CPT (Sigma). The analytical method was validated by testing for precision, accuracy, linearity, limits of detection and limit of quantification using standard methods. All experiments were repeated thrice. The effects of different treatments were quantified and the data subjected to statistical analysis using 'standard deviation of the mean'.

\section{Results and Discussion}

Leaf explants cultured on MS with different concentrations and combinations of NAA (1 - $5 \mathrm{mg} / \mathrm{l})$ and BA ( 0.5 - $5 \mathrm{mg} / \mathrm{l})$ demonstrated callus formation within 15 30 days of incubation. On varying concentration tested, the combination of NAA and BA found to be best for callus induction. The highest fresh weight of calli per explant was found on the medium containing growth regulators NAA $4 \mathrm{mg} / \mathrm{l}$ and BA $0.5 \mathrm{mg} / 1$ (Fig. 1A). In case of different concentrations of NAA showed optimal callus induction at $3 \mathrm{mg} / \mathrm{l}$. On the other hand BA showed better callus induction at $4 \mathrm{mg} / \mathrm{l}$ (Table 1$)$. 
Table 1. Effect of NAA and BA on callus formation from leaf segments of Ophiorrhiza eriantha after eight weeks of cultures.

\begin{tabular}{|c|c|c|c|}
\hline \multicolumn{2}{|c|}{$\begin{array}{l}\text { Growth regulators } \\
\qquad(\mathrm{mg} / \mathrm{l})\end{array}$} & \multirow[t]{2}{*}{$\begin{array}{c}\text { Mean fresh } \\
\text { weight of callus }\end{array}$} & \multirow{2}{*}{$\begin{array}{l}\text { Camptothecin content } \\
\text { (mg/g dry weight) } \\
\text { (gm) } \pm \text { S.D }\end{array}$} \\
\hline$\overline{\mathrm{NAA}}$ & $\mathrm{BA}$ & & \\
\hline 1 & - & $0.705 \pm 0.58$ & $0.002 \pm 0.001$ \\
\hline 2 & - & $0.978 \pm 0.53$ & $0.002 \pm 0.001$ \\
\hline 3 & - & $1.377 \pm 0.17$ & $0.003 \pm 0.001$ \\
\hline 4 & - & $1.085 \pm 0.98$ & $0.002 \pm 0.010$ \\
\hline 5 & - & $0.736 \pm 0.52$ & $0.001 \pm 0.015$ \\
\hline- & 1 & $0.248 \pm 0.16$ & $0.002 \pm 0.018$ \\
\hline- & 2 & $0.266 \pm 0.21$ & $0.004 \pm 0.001$ \\
\hline- & 3 & $0.322 \pm 0.13$ & $0.004 \pm 0.001$ \\
\hline- & 4 & $0.346 \pm 0.16$ & $0.007 \pm 0.003$ \\
\hline- & 5 & $0.310 \pm 0.13$ & $0.008 \pm 0.003$ \\
\hline 3 & 0.5 & $1.36 \pm 0.89$ & $0.002 \pm 0.001$ \\
\hline 3 & 1 & $1.10 \pm 0.94$ & $0.004 \pm 0.001$ \\
\hline 3 & 2 & $1.025 \pm 0.37$ & $0.010 \pm 0.03$ \\
\hline 3 & 3 & $1.30 \pm 0.67$ & $0.015 \pm 0.002$ \\
\hline 3 & 4 & $1.952 \pm 1.00$ & $0.017 \pm 0.062$ \\
\hline 4 & 0.5 & $2.40 \pm 1.02$ & $0.026 \pm 0.002$ \\
\hline$\underline{4}$ & 1 & $1.91 \pm 1.03$ & $0.027 \pm 0.003$ \\
\hline
\end{tabular}

Mean \pm SD for three replications (12 leaf segments for each replication). Values are means of three independent replicates \pm S.D.

Shoot regeneration from the calli were determined by the type of growth regulator, its concentration and combination. The eight-week-old compact calli derived from leaves were subcultured on MS supplemented with BA (1 - $5 \mathrm{mg} / \mathrm{l})$ alone or in combination with NAA $(1-5 \mathrm{mg} / \mathrm{l})$ for shoot induction. Multiple shoots were induced at different frequencies $(10-100 \%)$ by the culture on the medium containing the different concentration of hormones (Table 2). The percentage of cultures showing shoot regeneration and number of shoots per culture was higher on MS fortified with BA $5 \mathrm{mg} / \mathrm{l}$ (Fig. 1 B, C). On this medium a maximum $100 \%$ cultures showed shoot regeneration with 26.08 shoots per culture eight weeks after callus culture. When concentration of BA was increased beyond $5 \mathrm{mg} / \mathrm{l}$, there was no enhancement of multiple shoots. Shoots are also produced by the combinations fortified with NAA and BA. Among the NAA BA combinations NAA $3 \mathrm{mg} / \mathrm{l}$ and BA $2 \mathrm{mg} / \mathrm{l}$ showed good response. However, the number of shoots was found to be lesser than those treated with BA $5 \mathrm{mg} / \mathrm{l}$. Addition of cytokinin to the medium greatly improved the regeneration and frequency as reported previously (Denchev and Conger 1994). 
Table 2. Effect of growth-regulators on shoot differentiation from leaf derived callus of O. eriantha after eight weeks of cultures.

\begin{tabular}{|c|c|c|c|c|}
\hline \multicolumn{2}{|c|}{$\begin{array}{l}\text { Growth regulators } \\
(\mathrm{mg} / \mathrm{l}) \\
\end{array}$} & \multirow[t]{2}{*}{$\begin{array}{l}\text { Mean shoot } \\
\text { number }\end{array}$} & \multirow{2}{*}{$\begin{array}{c}\text { Percentage } \\
\text { of calli } \\
\text { forming shoots }\end{array}$} & \multirow[t]{2}{*}{$\begin{array}{l}\text { Camptothecin } \\
\text { content }\end{array}$} \\
\hline$\overline{\mathrm{NAA}}$ & $\overline{B A}$ & & & \\
\hline- & 1 & $8.5 \pm 3.17$ & 55.56 & $0.010 \pm 0.17$ \\
\hline- & 2 & $9.16 \pm 2.40$ & 64.67 & $0.0151 \pm 0.12$ \\
\hline- & 3 & $9.66 \pm 2.34$ & 83.32 & $0.019 \pm 0.23$ \\
\hline - & 4 & $13.41 \pm 2.42$ & 94.44 & $0.032 \pm 0.21$ \\
\hline- & 5 & $26.08 \pm 4.33$ & 100.00 & $0.0485 \pm 0.18$ \\
\hline 3 & 2 & $11.25 \pm 2.89$ & 41.21 & $0.019 \pm 0.12$ \\
\hline 4 & 1 & $3.75 \pm 2.08$ & 36.86 & $0.0112 \pm 0.002$ \\
\hline 4 & 0.5 & $2.78 \pm 1.60$ & 19.90 & $0.011 \pm 0.002$ \\
\hline
\end{tabular}

Mean \pm SD for three replications (12 callus pieces for each replication).

Table 3. Influence of different auxins on rooting of in vitro formed shoots of O. eriantha after eight weeks culture.

\begin{tabular}{lcccc}
\hline \multicolumn{2}{c}{\begin{tabular}{c} 
Growth regulators \\
\multicolumn{2}{c}{$(\mathrm{mg} / \mathrm{l})$}
\end{tabular}} & & $\begin{array}{c}\text { Percentage } \\
\text { of rooting }\end{array}$ & $\begin{array}{l}\text { Mean root } \\
\text { number }\end{array}$ \\
\hline NAA & IAA & IBA & & \\
\hline 1 & - & - & 78 & $6.8 \pm 1.22$ \\
2 & - & - & 82 & $7.5 \pm 2.15$ \\
3 & - & - & 88 & $8.5 \pm 1.13$ \\
4 & - & - & 85 & $6.7 \pm 2.09$ \\
- & 1 & - & 72 & $3.2 \pm 1.56$ \\
- & 2 & - & 78 & $3.8 \pm 1.24$ \\
- & 3 & - & 72 & $4.3 \pm 1.03$ \\
- & 4 & - & 90 & $3.1 \pm 1.32$ \\
- & - & 1 & 96 & $4.5 \pm 1.12$ \\
- & - & 2 & 98 & $5.6 \pm 2.11$ \\
- & - & 3 & 93 & $10.5 \pm 1.14$ \\
- & - & 4 & & $8.5 \pm 1.17$ \\
\hline
\end{tabular}

Mean \pm SD for three replications (12 cultures for each replication).

Healthy multiple shoots were separated and transferred to MS containing different auxins. Of the three auxins tried for root regeneration IBA was more responsive than NAA and IAA. The number of roots formed per shoot increased in response to increasing IBA concentration (Table 3). The highest number of root approximately 10.5 per shoots was produced on treatment containing IBA $3 \mathrm{mg} / \mathrm{l}$ (Fig. 1 D, E). But thin slender roots were produced at the base of the shoot with a frequency of $88 \%$ in the presence of NAA $3 \mathrm{mg} / \mathrm{l}$ with a mean number of 6.8 roots. Half strength of MS with IAA also induces rooting but the frequencies were lower and shorter roots than the medium containing IBA. Here the result 
showed consistency with other studies where the addition of IBA promotes the induction of roots in several systems including Citrus reticulata, Citrus limon (Singh et al. 1994), Artemisia judaica (Liu et al. 2003) Bixa orellana (Neto et al. 2003) and Dioscorea zingiberensis (Chen et al. 2003), Salvia sclarea (Liu et al. 2000), Ocimum basilicum (Sahoo et al. 1997).
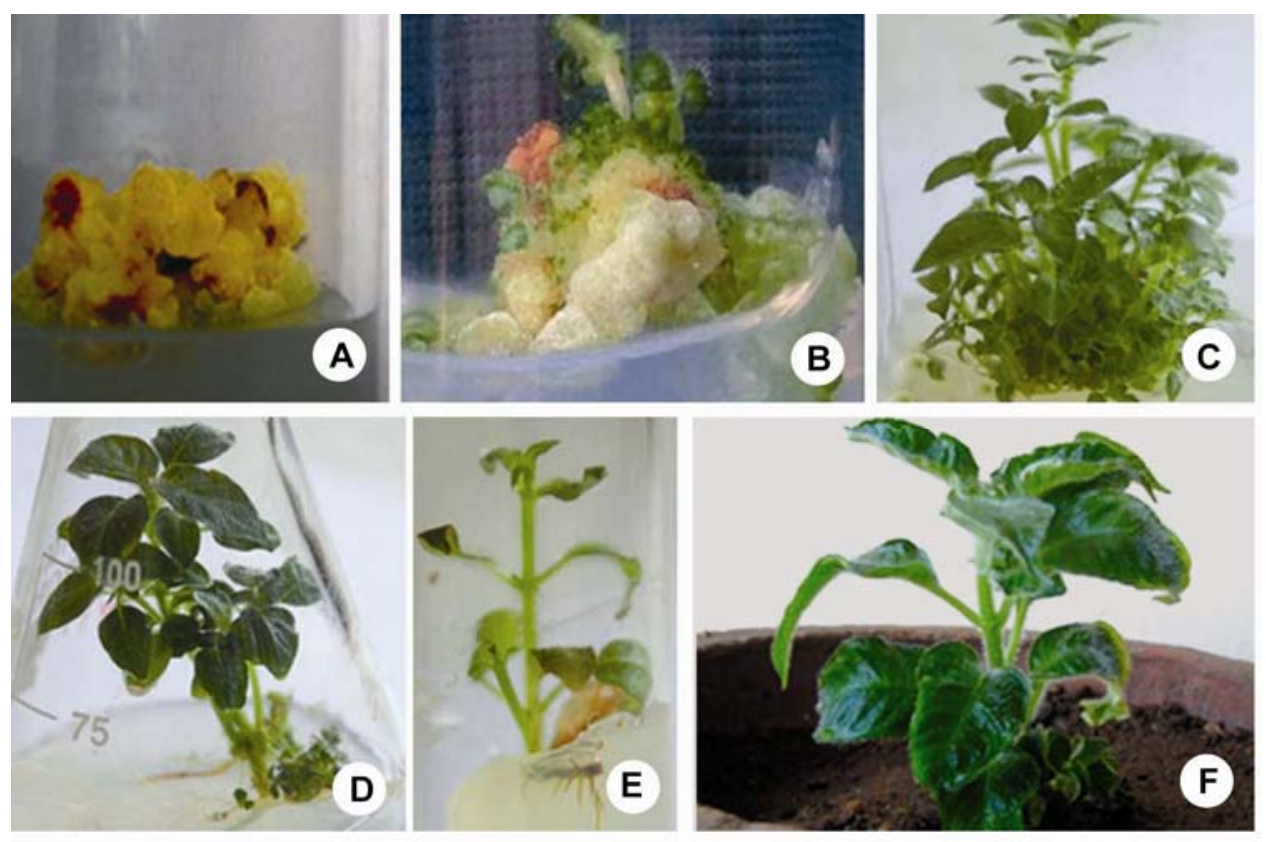

Fig. 1A-F: In vitro regeneration of Ophiorrhiza eriantha Wight. (A) callus induction, (B) initiation of multiple shoots from callus, (C) multiple shoot proliferation, (D) root initiation from excised shoot, (E) regenerated plantlets, $(F)$ hardened and acclimatized plant.

The in vitro raised healthy plantlets were transferred to earthen pots, gradually acclimatized and finally transferred to the field (Fig. 1 F).

The present study showed that the presence of CPT was confirmed in O. eriantha wild plant sample, callus and in vitro regenerated plantlets by LC-MSMS. Both the isolated CPT from O. eriatha and standard CPT were eluted at 4.94 min and with all the daughter ions eluting at the same time.

The wild O. eriantha whole plant contain $0.013 \mathrm{mg} / \mathrm{g}$ dry weight of CPT. The content of CPT were quantified in callus from different passages (V to VIII) growing on MS with NAA and BA and plantlets regenerated by tissue culture technique developed on MS with BA. CPT content in calluses seem to be somewhat lesser amount than regenerated plantlets.. The content of CPT in callus ranges from $0.004-0.027 \mathrm{mg} / \mathrm{g}$ of dry weight. The CPT content was highest ( $0.027 \mathrm{mg} / \mathrm{g}$ dry weight) in callus cultured with NAA $4 \mathrm{mg} / \mathrm{l}$ and BA $1 \mathrm{mg} / \mathrm{l}$. Roja and Heble (1994) reported traces of CPT production in Nothapodytes foetida 
callus cultures induced from immature embryos on defined medium. They have also suggested that biosynthesis of alkaloid was probably influenced by morphological differentiation. Whereas CPT concentration in the regenerated plants was higher with MS supplemented BA $5 \mathrm{mg} / 1$ (0.0485 mg/g dry weight). In vitro production CPT has been reported in C. acuminata. (Wiedenfield et al. 1997, Song and Byun 1998) and in Ophiorrhiza pumila (Kitajima et al. 1996).

Our finding that CPT concentration in the regenerated plants was significantly higher than that of the leaf derived calluses suggests that plant regeneration is a more efficient system than callus culture for CPT production in O. eriantha. Moreover CPT concentration in the regenerated plants was higher than in the ex vitro plants. Further optimization of production medium can lead to large scale commercial production of these alkaloids.

\section{Acknowledgement}

The authors wish to acknowledge the financial assistance from CSIR, New Delhi, in terms of grant to carry this work.

\section{References}

Bailly C (2003) Homocamptothecins: Potent topoisomerase I inhibitors and promising anticancer drugs. Crit. Rev. Oncol/Hematol. 45: 91-108.

Chen Y, Fan J, Yi F, Lou Z and Fu Y (2003) Rapid clonal propagation of Dioscorea zingiberensis. Plant Cell Tiss. Org. Cult. 73: 75-80.

Denchev PD and Conger BV (1994) Plant regeneration from callus cultures of Switchgrass. Crop Sci. 34: 1623-1627.

Hsiang YH, Hertzberg R, Hecht S and Liu LF (1985) Camptothecin induces protein linked DNA breaks via mammalian DNA topoisomerase I. J. Biol. Chem. 260: 1487314878.

Kitajima M, Makamura M, Masumoto S, Ohsawa M, Uneo M, Takayama H, Yamazaki M, Saito K, Aimi N and Stockigt J (1996) Production of camptothecinoids by utilising cell cultures of Ophiorrhiza pumila and synthetic studies of their related compounds. Tennen Yuki Kagodutsu Toronkai Koen Yoshishu 38: 238-288.

Kjeldsen E, Svejstrup JQ, Gromova II, Alsner J and Westergaard O (1992). Camptothecin inhibits both the cleavage and relegation of eukaryotic DNA topoisomerase I. J. Mol. Biol. 228: 1025-1030.

Liu CZ, Murch SJ, EL-Demerdash M and Saxena PK (2003) Regeneration of the Egyptian medicinal plant Artemisia judaica L. Plant Cell Rep. 21: 525-530.

Liu W, Chilcott CE, Reich RC and Hellmann GM (2000) Regeneration of Salvia sclarea via organogenesis. In Vitro Cell. Dev. Biol.Plant 36: 201-206.

Lorence A and Nessler CL (2004) Camptothecin, over four decades of surprising findings. Phytochemistry. 65: 2735-2749.

Neto VBP, Mota TR and Otoni WC (2003) Direct organogenesis from hypocotyls derived explants of annatto (Bixa orellana). Plant Cell Tiss. Org. Cult. 75: 159-167. 
Potmesil M (1994) Camptothecin from bench research to hospital wards. Cancer Res. 54: 1431-1439.

Priel E, Showalter SD and Blair DG (1991) Inhibition of human immunodeficiency virus (HIV -1) replication in vitro by non cytotoxic doses of camptothecin, a topoisomerase I inhibitor. AIDS Research and Human, Retroviruses 7: 65-72.

Roja G and Heble MR (1994) The Quinoline alkaloids camptothecin and methoxycamptothecin from tissue culture and mature trees of Nothapodytes foetida. Phytochemistry 36: 65-66.

Sahoo Y, Pattnaik SK and Chand PK (1997) In vitro clonal propagation of an aromatic medicinal herb Ocimum basilicum L. (sweet basil) by axillary shoot proliferation. In Vitro Cell. Dev. Biol. Plant 33: 293-296.

Saito K, Sudo H, Yamazaki M, Nakamura MK, Kitajima M, Takayama H and Aimi N (2001) Feasible production of camptothecin by hairy root culture of Ophiorrhiza pumila. Plant Cell Rep. 20: 267-271.

Singh S, Ray BK, Bhattacharyya S and Deka PC (1994) In vitro propagation of Citrus reticulate Blanco and Citrus limon Burm.f. Hort. Sci. 29: 214-216.

Song SH and Byun SY (1998) Characterization of cell growth and camptothecin production in cell cultures of Camptotheca acuminata. J. Microbiol. Biotechnol. 8: 631638.

Tafur S, Nelson JD, Delong DC and Svoboda GH (1976) Antiviral components of Ophiorrhiza mungos isolation of camptothecin and 10-methoxycamptothecin. Lloydia 39: 261-262.

Takeuchi A, Dohashi K, Fujimoto S, Tanaka K, Suzuki M, Terashima Y, Hasumi K, Akiya K, Negishi $Y$, Tamaya T, Tanizawa $O$, Sugawa T, Umesaki T, Hashimoto $M$, Yajima A, Yakamizawa H, Sonoda T, Takeda Y, Tomoda Y and Taguchi T (1991) A late phase II study of CPT-II in uterine cervical cancer and ovarian cancer. Jap. J. Cancer Chemother 18: 1681.

Thomas CJ, Rahier NJ, Hecht SM and Sidney M (2004) Camptothecin: Current perspectives. Bioorg. Med. Chem. 12:1585-1604.

Vineesh VR, Fijesh PV, Jelly Louis C, Jaimsha VK and Padikkala J (2007) In vitro production of camptothecin (an anticancer drug) from mutant albino plants of Ophiorrhiza rugosa var. decumbens. Cur. Sci. 92: 1219.

Wiedenfield H, Furmanowa M and Roeder E (1997) Camptothecin and 10-hydroxycamptothecin in callus and plantlets of Camptotheca acuminata. Plant Cell. Tiss. Org. Cult. 49: 213-218.

Zunino F and Pratesi G (2004) Camptothecin in clinical development. Expert Opin. Investig. Drugs 13: 269-284. 